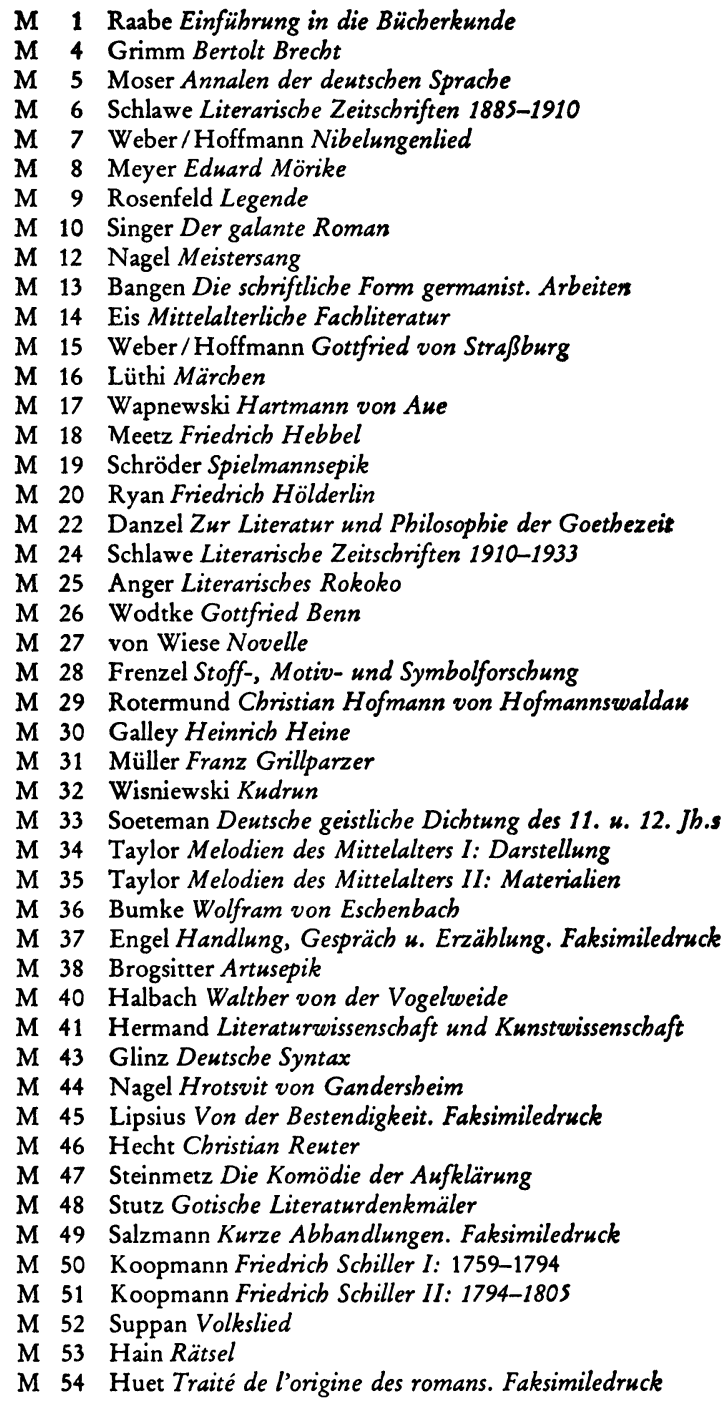




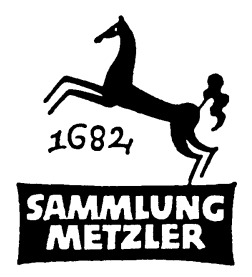

REALIEN ZUR LITERATUR

ABT. D:

LITERATURGESCHICHTE 
KARL S. GUTHKE

\section{Das deutsche bürgerliche Trauerspiel}

3., durchgesehene und erweiterte Auflage

MCMLXXX

J. B. METZLERSCHE VERLAGSBUCHHANDLUNG STUTTGART 
1. Auflage 1972 (1.-5. Tsd.)

2. Auflage 1976 (6.-10. Tsd.)

3. Auflage 1980 (11.-15. Tsd.)

CIP-Kurztitelaufnahme der Deutschen Bibliothek Guthke, Karl S.:

Das deutsche bürgerliche Trauerspiel /

Karl S. Guthke. - 3., durchges. u. erw. Aufl., (11. - 15. Tsd.) - Stuttgart: Metzler, 1980.

(Sammlung Metzler; 116: Abt. D,

Literaturgeschichte)

ISBN 978-3-476-13116-4

ISBN 978-3-476-13116-4

ISBN 978-3-476-98855-3 (eBook)

DOI 10.1007/978-3-476-98855-3

M 116

C 1980 Springer-Verlag GmbH Deutschland

Ursprünglich erschienen bei J. B. Metzlersche Verlagsbuchhandlung und Carl Ernst Poeschel Verlag GmbH in Stuttgart 1980. 
INHALT

Vorwort zur zweiten Auflage . . . . . . . . . . . VII

Vorwort zur dritten Auflage. . . . . . . . . . . . . VIII

I. Einführung: Bürgerliches Trauerspiel - eine literarische Gattung? . . . . . . . . . . . . . . . . 1

II. Anfänge und Grundlagen . . . . . . . . . . . 5

1. Wort und Begriff in der Entstehungszeit . . . . 5

2. Geistes- und literaturgeschichtliche Bedeutung des bürgerlichen Trauerspiels . . . . . . . 16

3. Vorgeschichte in Deutschland . . . . . . 20

4. Ausländische Anregungen . . . . . . . 26

III. »Miß Sara Sampson« und die Folgen . . . . . . 36

1. Empfindsamkeit und Bürgerlichkeit . . . . 36

2. Die Theorie des »Privat-Trauerspiels« . . . . . 42

3. Das empfindsame bürgerliche Trauerspiel . . . 50

IV. Von »Emilia Galotti "bis "Kabale und Liebe" . . 66

1. Standesbewußtsein und Gesellschaftskritik . . . 66

2. Lessing und die Sozialpolitisierung des bürgerlichen Trauerspiels . . . . . . . . . . 72

3. Spielarten des bürgerlichen Trauerspiels im Sturm und Drang . . . . . . . . . . . . 77

V. Verfall, Wandlung, Nachspiele . . . . . . . 90

1. Schwundformen in der Goethezeit . . . . . . 90

2. Das bürgerliche Tendenzdrama des Jungen Deutschland ............. . 93

3. Hebbel und die "Tragödie des Bürgertums« . . . 98

4. Ausblick . . . . . . . . . . . . . 104

Namenregister . . . . . . . . . . . . 109 


\section{ABKürzUngen}

\begin{tabular}{|c|c|}
\hline \multirow{6}{*}{$\begin{array}{l}\text { Abt. } \\
\text { ADB } \\
\text { bgl.Tr. } \\
\text { Diss. } \\
\text { DLD } \\
\text { dt. } \\
\text { DVjs. }\end{array}$} & \multirow{6}{*}{$\begin{array}{l}\text { Abteilung } \\
\text { Allgemeine Deutsche Biographie } \\
\text { bürgerliches Trauerspiel } \\
\text { Dissertation } \\
\text { Deutsche Literatur-Denkmäler } \\
\text { deutsch } \\
\text { Deutsche Vierteljahrsschrift für Literaturwissenschaft } \\
\text { und Geistesgeschichte }\end{array}$} \\
\hline & \\
\hline & \\
\hline & \\
\hline & \\
\hline & \\
\hline GLL & German Life and Letters \\
\hline $\mathrm{RM}$ & Germanisch-Romanische Monatsschrift \\
\hline & herausgegeben \\
\hline Jb. & Jahrbuch \\
\hline JEGP & Journal of English and Germanic Philology \\
\hline & Jahrhundert \\
\hline \multicolumn{2}{|c|}{ Lachmann/Muncker } \\
\hline & $\begin{array}{l}\text { G. E. Lessing, Sämtliche Schriften, hrsg. v. Karl } \\
\text { Lachmann. 3. Aufl. besorgt von Franz Muncker. } \\
23 \text { Bde. 1886-1924. }\end{array}$ \\
\hline Masch. & Maschinenschrift (ungedruckt) \\
\hline $\mathrm{LN}$ & Modern Language Notes \\
\hline ILR & Modern Language Review \\
\hline NDB & Neue Deutsche Biographie \\
\hline N.F. & Neue Folge \\
\hline \multicolumn{2}{|c|}{ Petersen/Olshausen } \\
\hline & $\begin{array}{l}\text { G. E. Lessing, Werke. Vollst. Ausg. in } 25 \text { Teilen, hrsg } \\
\text { v. Julius Petersen u. Waldemar v. Olshausen. [1925- } \\
\text { 35]. }\end{array}$ \\
\hline I & Reallexikon der dt. Literaturgeschichte \\
\hline & \\
\hline 3. & Leltsc \\
\hline
\end{tabular}




\section{VORWORT ZUR ZWEITEN AUfLAGE}

Für die Neuauflage wurden die Bibliographien auf den neusten Stand gebracht und die Textpartien einer gründlichen stilistischen und sachlichen Revision unterzogen. Dieser sind nicht nur die Besprechungen der ersten Auflage und die neueren Arbeiten zum bürgerlichen Trauerspiel sowie zu einzelnen Exemplaren der Gattung zugute gekommen, sondern auch die eigenen Studien der letzten Jahre, die zu meinem Buch "Literarisches Leben im 18. Jahrhundert in Deutschland und in der Schweiz « (Bern u. München: Francke, 1975) geführt haben.

Der Anforderung dieser Realienbuch-Reihe: kritische Information zu bieten, Urteil und Unparteilichkeit zu verbinden, ist in einer Darstellung des deutschen bürgerlichen Trauerspiels nicht leicht zur Zufriedenheit aller Kritiker zu genügen, da das bürgerliche Trauerspiel für viele ein Politikum geworden ist. Was den einen als Fairneß berührt, wirkt auf andere als Zuviel oder Zuwenig an Parteilichkeit. Davon unangefochten, habe ich es jedoch für angezeigt gehalten, meine grundsätzliche Skepsis gegenüber der landläufigen Vorstellung vom bürgerlichen Trauerspiel als kohärenter literarischer Gattung stärker (doch ohne die Verpflichtung zur Sachlichkeit weniger ernst zu nehmen) zu akzentuieren (s. besonders S. 1-4) - in der Hoffnung, dadurch ein kritisches Gespräch in Gang zu bringen über die immer noch viel zu wenig durchdachte Fundierung des Begriffs dieser Gattung in unausgesprochenen traditionellen wissenschaftlichen Vorentscheidungen. Für einen kritischen Anstoß in dieser Richtung danke ich außer den Rezensenten, die so freundlich waren, die eigenständige Forschungssubstanz dieses kleinen Handbuchs zu würdigen, besonders Herrn Dr. Reinhart Meyer, der mich auch auf drei als bürgerliche Trauerspiele bezeichnete Stücke sowie auf die Periochen von zwei verschollenen jesuitischen bürgerlichen Trauerspielen aufmerksam machte (s. u. S. 60), die mir in der ersten Auflage entgangen waren.

\section{Harvard University}

Dezember 1975

K. S. G. 


\section{VORWORT ZUR DRITTEN AUfLAGE}

Eine durchgreifende Revision der erst vor vier Jahren erschienenen zweiten Auflage, die ihrerseits eine intensive Überarbeitung der ersten darstellte, war nicht erforderlich. Neuere Forschungsliteratur wurde so vollständig wie möglich in den bibliographischen Abschnitten verzeichnet und, wo indiziert, in den Textpartien ausgewertet. Außerdem sind der Darstellung manche kleinere Berichtigungen und Ergänzungen zugute gekommen, die sich aus der Beschäftigung mit dem Thema in einem komparatistischen Seminar ergaben.

Harvard University

September 1979

K. S. G. 